\title{
Functionalized Au@Cu-Sb-S Nanoparticles for Spectral CT/Photoacoustic Imaging-Guided Synergetic Photo-Radiotherapy in Breast Cancer
}

\author{
Honglei Hu ${ }^{1,2, *}$, Shuting Zheng ${ }^{1,2, *}$, Meirong Hou ${ }^{1,2}$, Kai Zhu ${ }^{1,2}$, Chuyao Chen', Zede Wu ${ }^{1,2}$, Li Qi ${ }^{3}$, \\ Yunyan Ren', Bin Wu $\mathbb{D}^{4}$, Yikai Xu', Chenggong Yan ${ }^{1,5}$, Bingxia Zhao $\mathbb{D}^{2,6}$ \\ *These authors contributed equally to this work \\ 'Department of Medical Imaging Center, Nanfang Hospital, Southern Medical University, Guangzhou, 5I05I5, People's Republic of China; ${ }^{2}$ Guangzhou \\ Key Laboratory of Tumor Immunology Research, Cancer Research Institute, School of Basic Medical Sciences, Southern Medical University, \\ Guangzhou, 5 I05 I5, People's Republic of China; ${ }^{3}$ Guangdong Provincial Key Laboratory of Medical Image Processing, Guangdong Province Engineering \\ Laboratory for Medical Imaging and Diagnostic Technology, School of Biomedical Engineering, Southern Medical University, Guangzhou, 5I05I5, \\ People's Republic of China; ${ }^{4}$ Institute of Respiratory Diseases, Respiratory Department, The Affiliated Hospital of Guangdong Medical University, \\ Zhanjiang, 52400I, People's Republic of China; ${ }^{5}$ Guangdong Provincial Key Laboratory of Shock and Microcirculation, School of Basic Medical \\ Sciences, Southern Medical University, Guangzhou, 510515, People's Republic of China; ${ }^{6}$ Experimental Education/Administration Center, School of \\ Basic Medical Science, Southern Medical University, Guangzhou, 5I05I5, People's Republic of China
}

Correspondence: Bingxia Zhao; Yikai Xu, Tel +86 20 61647272; +8620 62787333, Email bingxiaz@gmail.com; yikaixu917@gmail.com

Background: Radiotherapy (RT) is clinically well-established cancer treatment. However, radioresistance remains a significant issue associated with failure of RT. Phototherapy-induced radiosensitization has recently attracted attention in translational cancer research. Methods: $\mathrm{Cu}-\mathrm{Sb}-\mathrm{S}$ nanoparticles (NPs) coated with ultra-small Au nanocrystals (Au@Cu-Sb-S) were synthesized and characterized. The biosafety profiles, absorption of near-infrared (NIR) laser and radiation-enhancing effect of the NPs were evaluated. In vitro and in vivo spectral computed tomography (CT) imaging and photoacoustic (PA) imaging were performed in 4T1 breast cancer-bearing mice. The synergetic radio-phototherapy was assessed by in vivo tumor inhibition studies.

Results: $\mathrm{Au} @ \mathrm{Cu}-\mathrm{Sb}-\mathrm{S}$ NPs were prepared by in situ growth of Au NCs on the surface of Cu-Sb-S NPs. The cell viability experiments showed that the combination of $\mathrm{Au} @ \mathrm{Cu}-\mathrm{Sb}-\mathrm{S}+\mathrm{NIR}+\mathrm{RT}$ was significantly more cytotoxic to tumor cells than the other treatments at concentrations above $25 \mathrm{ppm}$ Sb. In vitro and in vivo spectral CT imaging demonstrated that the X-ray attenuation ability of Au@Cu$\mathrm{Sb}-\mathrm{S}$ NPs was superior to that of the clinically used Iodine, particularly at lower KeV levels. Au@Cu-Sb-S NPs showed a concentration-dependent and remarkable PA signal brightening effect. In vivo tumor inhibition studies showed that the prepared $\mathrm{Au} @ \mathrm{Cu}-\mathrm{Sb}$-S NPs significantly suppressed tumor growth in 4T1 breast cancer-bearing mice treated with NIR laser irradiation and an intermediate X-ray dose (4 Gy).

Conclusion: These results indicate that $\mathrm{Au} @ \mathrm{Cu}-\mathrm{Sb}-\mathrm{S}$ integrated with spectral CT, PA imaging, and phototherapy-enhanced radiosensitization is a promising multifunctional theranostic nanoplatform for clinical applications.

Keywords: Au@Cu-Sb-S nanoparticle, phototherapy, radiotherapy, spectral CT, photoacoustic imaging

\section{Introduction}

Radiotherapy (RT), which utilizes high energy ionizing radiation (eg, X-ray) to induce cell apoptosis, is widely used for treatment of the solid tumors, such as lung, breast and rectal cancer. ${ }^{1-3}$ However, the low absorption rate of radiation in tumor tissue can lead to radiotherapy resistance. ${ }^{4-7}$ Recently, phototherapy-enhanced radiotherapy has received considerable attention in translational cancer treatment research. On one hand, radiotherapy exerts limited inhibitory effects on hypoxic solid tumors, while the oxygenation status in the tumor can be improved by the enhanced intratumoral blood flow induced by the photothermal effect, endowing tumor cells with high sensitivity to radiotherapy. On the other hand,

Received: 10 September 2021

Accepted: 6 January 2022

Published: 25 January 2022
International Journal of Nanomedicine 2022: 17 395-407

(c) (7) ( 2022 Hu et al. This work is published and licensed by Dove Medical Press Limited. The full terms of this license are available at https://www.dovepress.com/terms.php (c) ${ }_{\mathrm{BY}} \mathrm{NC}$ and incorporate the Creative Commons Attribution - Non Commercial (unported, v3.0) License (http://creativecommons.org/licenses/by-nc/3.0/). By accessing the work you hereby accept the Terms. Non-commercial uses of the work are permitted without any further permission from Dove Medical Press Limited, provided the work is properly attributed. For permission for commercial use of this work, please see paragraphs 4.2 and 5 of our Terms (https://www.dovepress.com/terms.php). 
The PDT induced ROS could not only fulfill phototherapy, but also potentially consume the intracellular antioxidant GSH, therefore enhance effect of radiotherapy. What's more, cancer cells that are resistant to radiotherapy could be killed by phototherapy. ${ }^{8-12}$

High atomic number $(\mathrm{Z})$ metals, including platinum, ${ }^{13}$ gold, ${ }^{13-15}$ and bismuth, ${ }^{16}$ have been successfully used as radiotherapy sensitizers to increase the efficacy of external radiation, a process known as radiosensitization. Gold (Au) is a typical high- $Z$ element that is considered an excellent radiotherapy sensitizer because of its higher mass energy absorption coefficients, which results in amplified radiation dose deposition. ${ }^{17-21} \mathrm{Cu}-\mathrm{Sb}-\mathrm{S}$ nanoparticles (NPs), a novel nanotheranostic agent with excellent phototherapeutic efficiency developed by our group, ${ }^{22}$ are a promising nanoplatform to increase the radiosensitivity of tumor tissue. Integration of $\mathrm{CuS}$ and nanoscale $\mathrm{Au}$ NPs enhances the photothermal effect, which is attributed to the strong coupling effect between $\mathrm{Au}$ and $\mathrm{CuS}$ (or BiS). ${ }^{23-25}$

The intrinsic radiosensitization ability of the Au element combined with its X-ray attenuation abilities suggest that Au-based NPs are a potential computed tomography (CT) contrast agent. ${ }^{12,26-30} \mathrm{CT}$ is one of the most commonly used imaging modalities for clinical disease diagnosis, and it has several advantages such as noninvasiveness, deep tissue penetration, and multi-planar image reconstruction. However, it is challenging for conventional CT to distinguish tissues with different density and different X-ray excitation energies. Unlike traditional $\mathrm{CT}$, spectral $\mathrm{CT}$ decomposes the traditional polyenergetic $\mathrm{X}$-ray beam into continuous single energies ranging from 40 to $140 \mathrm{KeV}$, which may achieve qualitative separation and quantitative determination of substances. ${ }^{31-36}$ For example, Metin et $\mathrm{al}^{31}$ found that the conspicuity of primary breast cancer was significantly higher in low $\mathrm{KeV}$ virtual monochromatic images. Thus, the combination of spectral CT and high-Z nanomaterials shows potential for the accurate diagnosis of various diseases.

In this work, a multifunctional nanoplatform based on Au@Cu-Sb-S NPs was successfully developed (Scheme 1). We confirmed that the developed $\mathrm{Au} @ \mathrm{Cu}-\mathrm{Sb}-\mathrm{S}$ NPs functioned as an excellent contrast agent for spectral CT and PA imaging. In addition, we showed that the $\mathrm{Au} @ \mathrm{Cu}-\mathrm{Sb}-\mathrm{S}$ nanoplatform had synergistic antitumor effects with

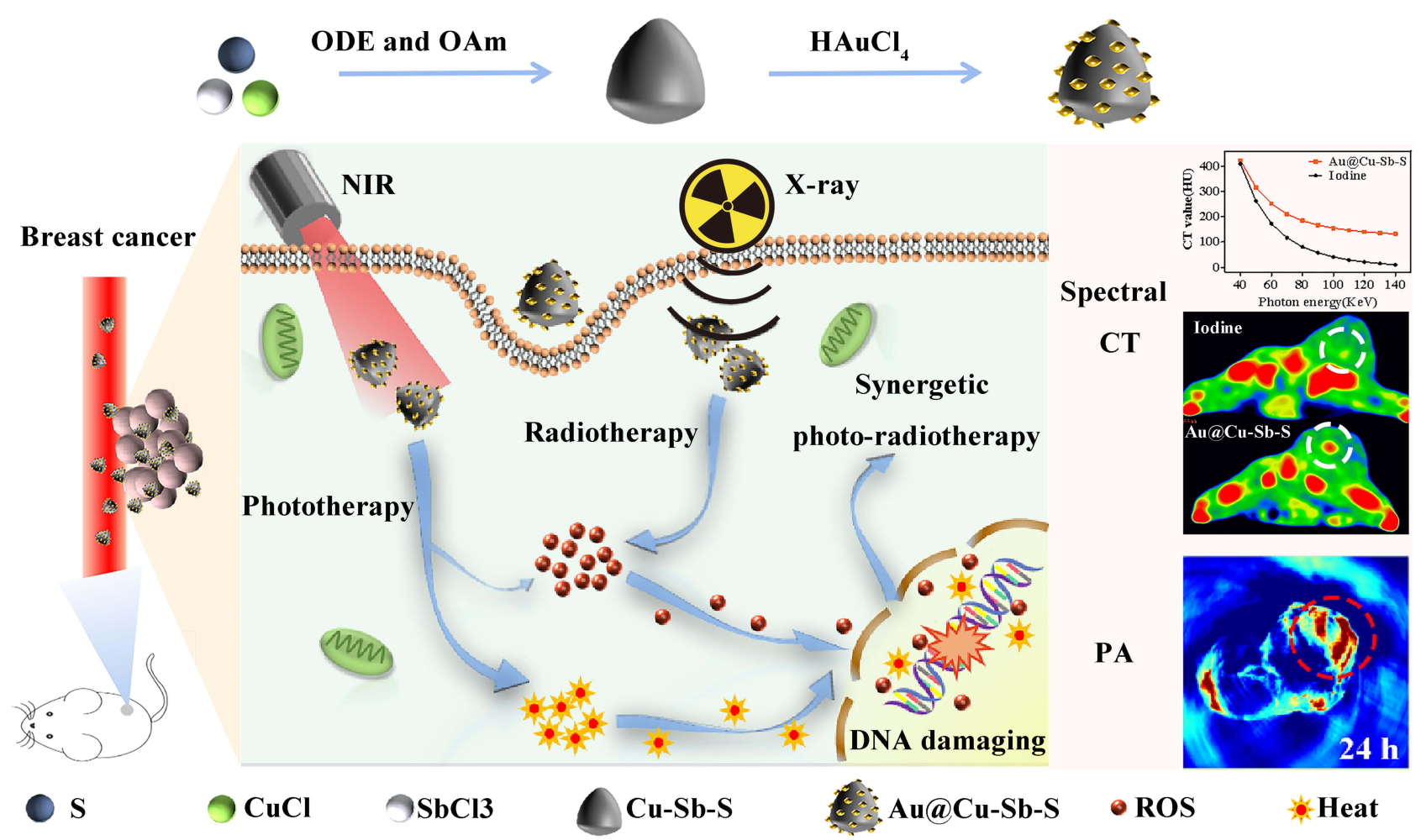

Scheme I Schematic illustration of the mechanism of Au@Cu-Sb-S nanoparticles (NPs) in the diagnosis and treatment of breast cancer. 
phototherapy-enhanced RT. The present results demonstrated that $\mathrm{Au} @ \mathrm{Cu}-\mathrm{Sb}-\mathrm{S}$ NPs was a promising theranostic agent for diagnostic imaging and combination treatment for breast cancer.

\section{Materials and Methods \\ Materials}

Gold (III) chloride trihydrate $\left(\mathrm{HAuCl}_{4} \cdot 3 \mathrm{H}_{2} \mathrm{O}, 99 \%\right)$, copper(I) chloride (CuCl, 99.995\%), antimony (III) chloride $\left(\mathrm{SbCl}_{3}\right.$, 99.9\%), sulphur (S) powder (99.98\%), 1-octadecene (ODE) and Oleylamine (OAm) were purchased from Macklin (Guangzhou, China). RPMI-1640 and fetal bovine serum (FBS) were purchased from Gibco (ThermoFisher, America). The mouse breast cancer cell line 4T1 was provided by Procell Life Science \& Technology Co., Ltd. which was a stock cell line passaged by FuDan IBS Cell Center. The use of the cell lines was approved by the Laboratory Animal Management Committee of Nanfang Hospital.

\section{Preparation of Cu-Sb-S NPs and Au Precursors}

The synthesis of $\mathrm{Cu}-\mathrm{Sb}-\mathrm{S}$ NPs was performed as described previously. ${ }^{22}$ The Au precursor was prepared by fully dissolving $0.3 \mathrm{mmol} \mathrm{HAuCl} 4 \cdot 3 \mathrm{H}_{2} \mathrm{O}$ in a mixture of $3 \mathrm{~mL} \mathrm{OAm}$ and $1 \mathrm{~mL}$ toluene via sonication for $20-30 \mathrm{~min}$.

\section{Synthesis and Modification of Au@Cu-Sb-S NPs}

$\mathrm{Au} @ \mathrm{Cu}-\mathrm{Sb}-\mathrm{S}$ NPs were prepared as described in previous publications with a minor modification. ${ }^{22,24}$ Typically, $\mathrm{Cu}-\mathrm{Sb}-$ $\mathrm{S}$ NPs were mixed with $\mathrm{Au}$ precursor in OAm/toluene. Au precursor $(750 \mu \mathrm{L}$ and $12 \mathrm{~mL}$, containing 0.056 and $0.896 \mathrm{mmol} \mathrm{Au}$, respectively) was mixed with $6 \mathrm{~mL}$ toluene, $9 \mathrm{~mL} \mathrm{OAm}$, and $500 \mu \mathrm{L} \mathrm{Cu}-\mathrm{Sb}-\mathrm{S} \mathrm{NP}$ dispersion. Excluding losses of $\mathrm{Cu}$ during synthesis and purification of $\mathrm{Cu}-\mathrm{Sb}-\mathrm{S}$ NPs, this preparation would contain an estimated $0.225 \mathrm{mmol} \mathrm{Cu}$. Thus, the ratio of $\mathrm{Au}$ added to the $\mathrm{Cu}$ used in preparing the NPs was 1:4 and 4:1, respectively. Under an $\mathrm{N}_{2}$ atmosphere, the mixture was heated to $55^{\circ} \mathrm{C}$ for $90 \mathrm{~min}$ with vigorous stirring in a three-necked bottle, and then cooled to room temperature for collection. PVP modification was performed by dissolving $\mathrm{Au} @ \mathrm{Cu}-\mathrm{Sb}-\mathrm{S}$ NPs in chloroform $(20 \mathrm{~mL})$ and then adding PVP $(1.2 \mathrm{~g})$ with stirring for $48 \mathrm{~h}$ at room temperature. After chloroform evaporation, the precipitate was washed three times with deionized water.

\section{Characterization}

The size and morphology of Au@Cu-Sb-S NPs were characterized using transmission electron microscope (TEM) and high-resolution transmission electron microscopy (HRTEM) (JEM 2100F, Japan) at a working voltage of $200 \mathrm{kV}$. Elemental analysis of Au@Cu-Sb-S NPs was performed using energy dispersive X-ray spectrometry (EDS) on a Thermol UltraDry EDS system. The crystal structures of Au@Cu-Sb-S NPs were determined by powder X-ray diffraction (XRD) using an Empyrean diffractometer. Optical absorption spectra of Cu-Sb-S NPs and Au@Cu-Sb-S NPs were obtained using a spectrophotometer (UV-3600, Japan) and UV-Vis Spectrophotometer (Agilent Cary 60, USA). The element concentrations of Cu-Sb-S NPs and Au@Cu-Sb-S NPs were obtained by inductively coupled plasma optical emission spectroscopy (ICP-OES).

\section{Photothermal Effect}

Aqueous solutions of various nanomaterials [Cu-Sb-S NPs, Au@Cu-Sb-S(1-4) NPs, Au@Cu-Sb-S(4-1) NPs] at different concentrations $(0,12.5,25,50$, and $100 \mathrm{ppm}$, based on the concentration of Sb element in NPs) were treated with $808 \mathrm{~nm}$ laser (10 min, $1 \mathrm{~W} \mathrm{~cm}^{-2}$ ). The changes in temperature and thermal images of these solutions were recorded in real time using a FILR thermal camera. To evaluate the photothermal stability of Au@Cu-Sb-S NPs, solution of 100 ppm Sb Au@Cu-Sb-S(1-4) NPs and Au@Cu-Sb-S(4-1) NPs were irradiated in four heating-cooling cycle modes (808 $\mathrm{nm}, 10 \mathrm{~min}, 1 \mathrm{~W} \mathrm{~cm}^{-2}$ ). 


\section{Cytotoxicity Assays}

Cell viability in response to $\mathrm{Au} @ \mathrm{Cu}$-Sb-S NPs was assessed using the standard Cell Counting Kit 8 (CCK-8) assay. The $4 \mathrm{~T} 1$ cells were cultured in RPMI-1640 medium supplemented with $10 \%$ fetal bovine serum (FBS) at $37^{\circ} \mathrm{C}$ under a humid atmosphere containing $5 \% \mathrm{CO}_{2}$. The cells were seeded in a 96 -well plate at a density of 8000 cells per well and incubated for 24 h. Then, medium containing Au@Cu-Sb-S NPs at different concentrations $(0,12.5,25,50$, and 100 ppm Sb) was added to replace the original culture medium, and after another day of incubation, 10\% CCK-8 solution was added to each well and the cells were incubated for $0.5 \mathrm{~h}$. Finally, cell viability was measured using an enzyme-linked immunosorbent assay reader (BIOTEK ELX80, Holland) at $450 \mathrm{~nm}$.

\section{Colony Formation}

The 4T1 cells were seeded on 6-well plates and incubated with or without Au@Cu-Sb-S NP (25 Sb ppm) for 24 h, followed by exposure $0,2,4,6$, and 8 Gy X-ray irradiation. Cells were placed in an incubator at $37^{\circ} \mathrm{C}$ for 8 days, and the medium was changed several times during this period. The final staining with Crystal Violet was performed for display.

\section{In vitro Assessment of Free Radicals Generation}

Cells were divided into eight groups: PBS, PBS+NIR(ice), PBS+RT, PBS+NIR+RT, Au@Cu-Sb-S NPs, Au@Cu-Sb-S NPs+NIR(ice), Au@Cu-Sb-S NPs+RT, and Au@Cu-Sb-S NPs+NIR+RT. First, 4T1 cells were seeded in a 96-well plates for $24 \mathrm{~h}$. Then the old medium was replaced with medium containing PBS or Au@Cu-Sb-S NPs (25 ppm Sb) and incubation was continued for another $24 \mathrm{~h}$. Next, the different groups were subjected to different treatments. The groups containing NIR were treated with $808 \mathrm{~nm}$ laser $\left(5 \mathrm{~min}, 1 \mathrm{~W} \mathrm{~cm}^{-2}\right)$ and the NIR (ice) groups performed NIR treatment on ice in order to explore the effect of pure NIR (excluding the effect of heat production) on cell production of ROS. The groups containing RT were exposed to X-ray irradiation (4 Gy). DCFH-DA $(10 \mu \mathrm{mol} / \mathrm{L})$ was added into each well for 30 min after removing the medium and washing twice with PBS. The final results were observed using a fluorescent microscope (OLYMPUS IX71, Japan) and flow cytometry.

\section{In vitro Antitumor Effect}

The Cell Counting Kit 8 (CCK-8) assay was used to assess cell viability in response to the different treatments (Au@CuSb-S NPs, only RT, Au@Cu-Sb-S NPs+NIR, Au@Cu-Sb-S NPs+RT, and Au@Cu-Sb-S NPs+NIR+RT). For details, refer to the in vitro cytotoxicity study. Live/dead cell staining was performed with calcein AM $(1 \mu \mathrm{M})$ and propidium iodide $(1 \mu \mathrm{M})$, and live cells (green color) and dead cells (red color) were distinguished by fluorescence microscopy. In addition, 4T1 cells were planted on a 6-well plate at a density of $3 \times 10^{5}$ cells per well and incubated at $37 \%$ and $5 \% \mathrm{CO}_{2}$ for 24 h. The complete medium containing Au@Cu-Sb-S NPs (25 Sb ppm) was replaced and cells were incubated for $24 \mathrm{~h}$. The intervention conditions were $1 \mathrm{~W} \mathrm{~cm}{ }^{-2}, 808 \mathrm{~nm}$ laser irradiation for $5 \mathrm{~min}$ and $4 \mathrm{~Gy} \mathrm{X}$-ray irradiation. After another $24 \mathrm{~h}$ of incubation, the cells were collected and stained with Annexin V/PI and finally analyzed by a flow cytometry.

\section{Animal Experiments}

Female BALB/c mice (4-6 weeks) used in this study were purchased from Animal Laboratory of Nanfang Hospital of Southern Medical University (Guangzhou, China). All animal care and in vivo studies were approved by the Laboratory Animal Management Committee of Nanfang Hospital and performed in compliance with the ethical principles of the Experimental Animal Welfare Ethics Committee of Nanfang Hospital (approval NFYY-2018-129). Mice bearing 4T1 tumors were exografted by subcutaneous inoculation of $1 \times 10^{6}$ cells in $150 \mu \mathrm{L}$ PBS into the right-flank. When the tumor grew to $80-100 \mathrm{~mm}^{3}$, the mice were used for experiments.

\section{Photoacoustic (PA) Imaging}

In vitro PA imaging of $\mathrm{Au} @ \mathrm{Cu}-\mathrm{Sb}-\mathrm{S}$ NPs with different $\mathrm{Sb}$ concentrations of 0, 12.5, 25, 50, and 100 ppm Sb was performed at different wavelengths using with the multispectral optoacoustic tomography (MSOT) system (iThera 
Medical GmbH, Neuherberg, Germany). The slope was calculated by the fitting curve of the average PA signal intensity versus the concentration of $\mathrm{Au} @ \mathrm{Cu}-\mathrm{Sb}-\mathrm{S}$ NPs. The mice were subjected to PAI at a wavelength of $780 \mathrm{~nm}$ at different time points of $0,1,3,6,12$, and $24 \mathrm{~h}$ after the tail vein injection of Au@Cu-Sb-S NPs (100 Sb ppm, $300 \mu \mathrm{L})$.

\section{Spectral CT Imaging}

The performance of Au@Cu-Sb-S NPs in spectral CT (GE discovery CT 750 HD, Healthcare) was compared using commercial iopromide in vitro. The mass concentrations were changed from $0.1,0.5,1,2,3,4,5$, and $5.5 \mathrm{mg} \mathrm{mL}^{-1}$. For in vivo $\mathrm{CT}$ imaging, the mice received intratumor injection of $25 \mu \mathrm{L} \mathrm{Au} @ \mathrm{Cu}-\mathrm{Sb}-\mathrm{S}$ NPs and Iodine $(\mathrm{Au} / \mathrm{I}$ concentration of the solution was 2 or $5.5 \mathrm{mg} \mathrm{mL}^{-1}$ ) and scanned by CT under different $\mathrm{KeV}$ values 5 minutes after injection.

\section{In vivo Bio-Distribution Assay}

A total of $10 \mathrm{mg} \mathrm{Au} @ \mathrm{Cu}-\mathrm{Sb}-\mathrm{S}$ NPs and $30 \mathrm{mg}$ PEG-NH $\mathrm{N}_{2}$ were dissolved in $7 \mathrm{~mL}$ chloroform, stirred overnight at room temperature, chloroform was evaporated and collected by centrifugation. The product was dissolved in $10 \mathrm{~mL}$ of pure water and then added dropwise to the IR825 solution after carboxyl activation, collected after stirring overnight. The 4T1-tumor bearing mice were injected intravenously with $50 \mu \mathrm{L}$ IR825@Au@Cu-Sb-S NPs (1000 Sb ppm) and imaged under IVIS Lumina System (IVIS Lumina II, USA) at predetermined time points.

\section{In vivo Anti-Tumor Studies}

The tumor-bearing mice were randomly divided into five groups $(\mathrm{n}=5)$ as follows: saline, $\mathrm{Au} @ \mathrm{Cu}-\mathrm{Sb}-\mathrm{S} \mathrm{NPs,Au@Cu-}$ Sb-S NPs+NIR, Au@Cu-Sb-S NPs+RT, and Au@Cu-Sb-S NPs+NIR+RT. A total of $300 \mu \mathrm{L} \mathrm{Au@Cu-Sb-S} \mathrm{NPs} \mathrm{solution}$ with a concentration of $100 \mathrm{ppm} \mathrm{Sb}$ or saline was injected into the tumor-bearing mice through the tail vein. The power density and the irradiation time related to NIR irradiation were $1 \mathrm{~W} \mathrm{~cm}^{-2}$ and $5 \mathrm{~min}$, respectively. The real-time temperature and thermal images of mice were monitored using a FLIR thermal camera during the irradiation. RT was performed using 4 Gy X-ray release (MultiRad Faxitron, USA). The weights and tumor volumes of the mice were also constantly measured and recorded every other day during the treatment period. Tumor volumes were calculated using the formula $\mathrm{V}=$ length $\times$ width $^{2} / 2$. Mice in each group were sacrificed on the 21 st day after treatment. The tumors, main organs (heart, liver, spleen, lung and kidney), and blood were harvested for hematoxylin and eosin (H\&E) staining, terminal deoxynucleotidyl transferase-mediated dUTP-biotin nick end labeling (TUNEL) staining, and blood biochemical experiments.

\section{Results and Discussion}

\section{Synthesis and Characterization of Au@Cu-Sb-S NPs}

$\mathrm{Cu}-\mathrm{Sb}-\mathrm{S}$ NPs were synthesized using a previously reported method with slight modifications. ${ }^{22} \mathrm{Au} @ \mathrm{Cu}-\mathrm{Sb}-\mathrm{S}$ NPs were prepared by in situ growth of Au NCs on the surface of Cu-Sb-S NPs. TEM and HRTEM images showed Au@Cu-Sb-S NPs with an average diameter of $22.9 \pm 1.8 \mathrm{~nm}$ and Au uniformly decorated on the surface of $\mathrm{Cu}-\mathrm{Sb}-\mathrm{S}$ NPs (Figure S1A and $\underline{B}$ ). The elements $\mathrm{Au}, \mathrm{Cu}, \mathrm{Sb}$, and $\mathrm{S}$ in $\mathrm{Au} @ \mathrm{Cu}-\mathrm{Sb}-\mathrm{S}$ NPs were identified by TEM-EDS (Figure S1C). The growth of $\mathrm{Au}$ had no obvious influence on the size distribution and morphology of $\mathrm{Cu}-\mathrm{Sb}-\mathrm{S}$ NPs (Figure 1A-C). In response to increasing $\mathrm{Au}$ precursor, the $\mathrm{Au} / \mathrm{Cu}$ ratio increased, whereas the amount of $\mathrm{Sb}$ and $\mathrm{S}$ remained relatively constant (Figure 1D). The revolution of morphology and element ratio indicated that $\mathrm{Cu}$ ions on the surface were gradually exchanged by Au ions, forming the Au@Cu-Sb-S NPs. The relatively fixed Sb atomic ratio of $\mathrm{Au} @ \mathrm{Cu}-\mathrm{Sb}-\mathrm{S}$ NPs provided a basis for subsequent experiments. The X-ray powder diffraction (XRD) patterns were used to confirm the crystal structure of $\mathrm{Au} @ \mathrm{Cu}-\mathrm{Sb}-\mathrm{S}$ NPs, which showed that all peaks of Au@Cu-Sb-S(1-4) NPs and Au@Cu-Sb-S(4-1) NPs matched with $\mathrm{Au} \mathrm{NCs}$ and $\mathrm{Cu}_{12} \mathrm{Sb}_{4} \mathrm{~S}_{13}$ NPs. In addition, all peaks of Au NCs in $\mathrm{Au} @ \mathrm{Cu}-\mathrm{Sb}-\mathrm{S}(4-1) \mathrm{NPs}$ were significantly higher than those in $\mathrm{Au} @ \mathrm{Cu}-\mathrm{Sb}-\mathrm{S}(1-4) \mathrm{NPs}$ (Figure 1E). The water-solubility and stability of Au@CuSbS NPs were shown in Figure S2. No visible precipitation was observed in four different solutions (Pure water, PBS, RPMI1640 and RPMI-1640 with 10\% FBS) containing the Au@Cu-Sb-S(4-1) NPs (25 ppm Sb) over time. The morphology and size of $\mathrm{Au} @ \mathrm{Cu}-\mathrm{Sb}-\mathrm{S}(4-1) \mathrm{NPs}$ remained unchanged after 1 week of synthesis. 
A
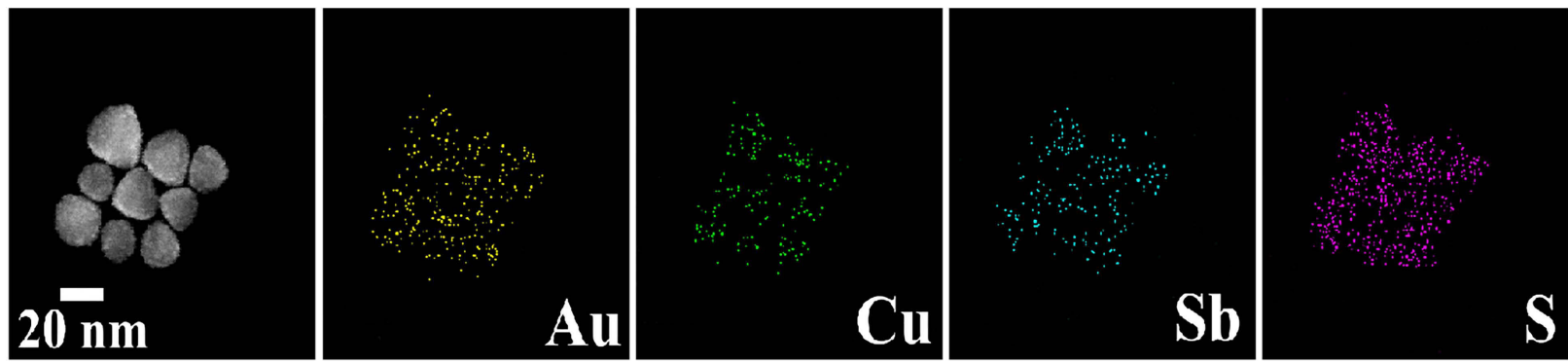

B

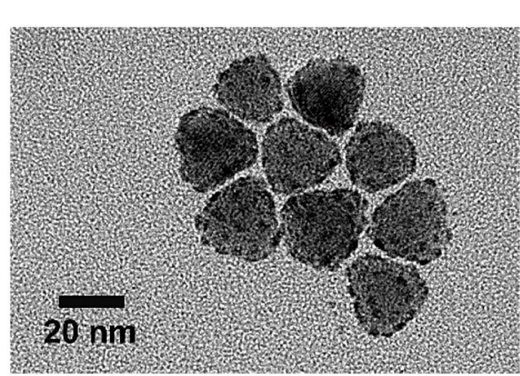

C

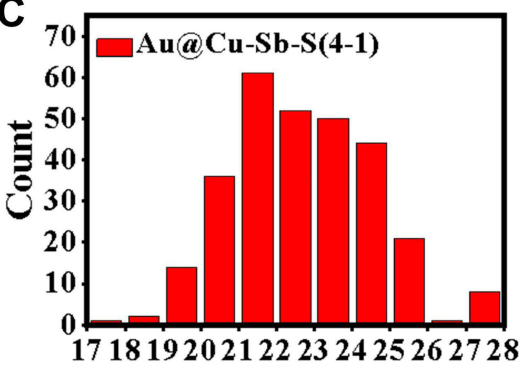

Diameter(nm)
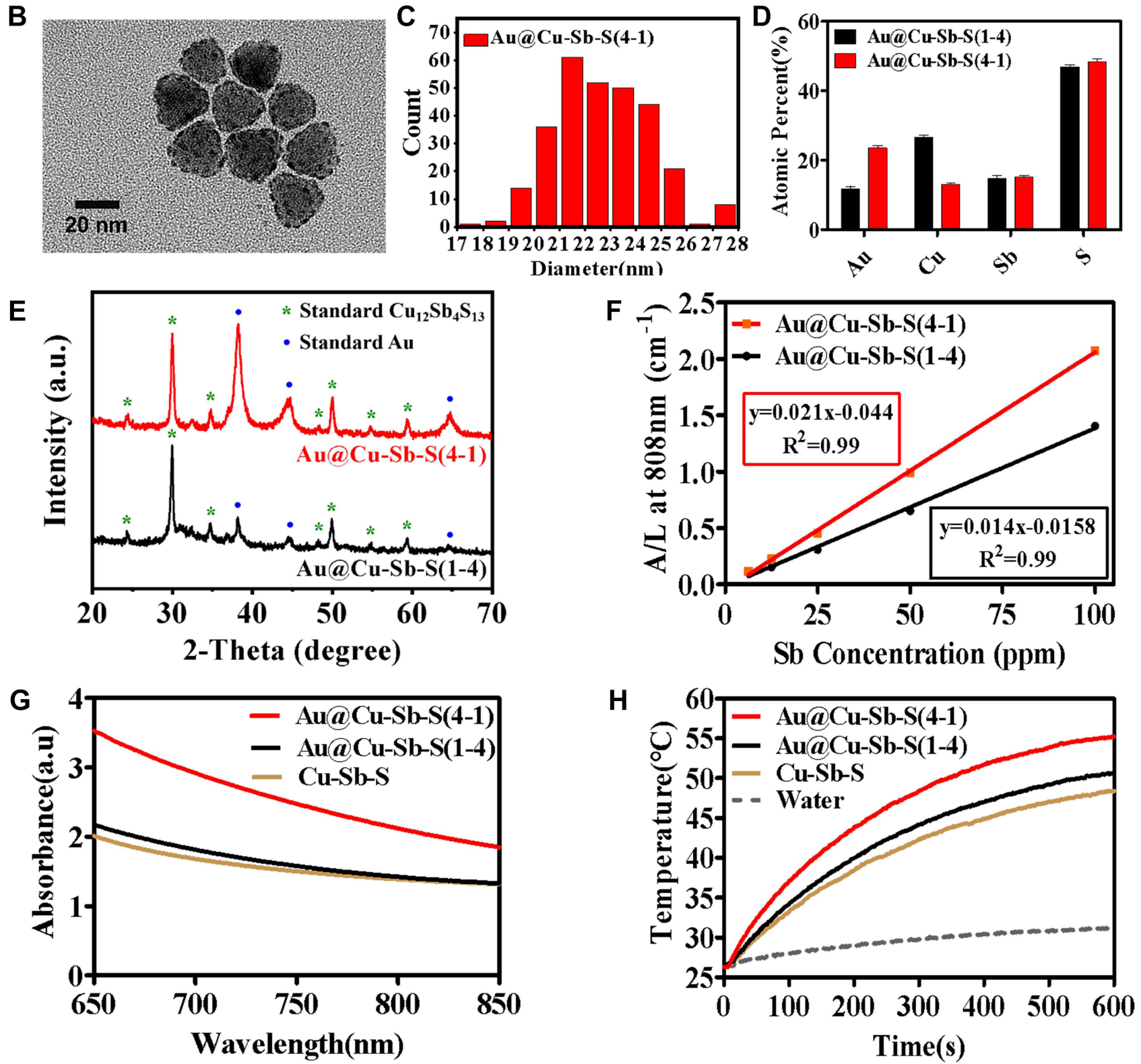

Figure I Characterization of Au@Cu-Sb-S nanoparticles (NPs) with different gold-to-copper ratios. (A) TEM-EDS elemental maps of Au@Cu-Sb-S NPs. (B) Transmission electron microscopy (TEM) image of Au@Cu-Sb-S(4-I) NPs. (C) Particle size distribution of Au@Cu-Sb-S(4-I) NPs. (D) Compositional analysis of Au@Cu-Sb-S NPs obtained from TEM-energy-dispersive X-ray spectroscopy (EDS). (E) XRD spectra of Au@Cu-Sb-S NPs. (F) Mass extinction coefficient of Au@Cu-Sb-S(I-4) NPs and Au@Cu-Sb-S(4-I) NPs under an 808 nm laser. (G) UV-vis-NIR absorbance spectrum of Cu-Sb-S NPs, Au@Cu-Sb-S(I-4) NPs and Au@Cu-Sb-S(4-I) NPs with the same Sb concentration (I00 Sb ppm). (H) Heating curves of pure and different NPs (Cu-Sb-S NPs, Au@Cu-Sb-S(I-4) NPs and Au@Cu-Sb-S(4-I) NPs) with the same I00 ppm Sb concentration. 


\section{In vitro NIR Absorbance and Photo-Responsive Effect}

To further study the properties of $\mathrm{Au} @ \mathrm{Cu}-\mathrm{Sb}-\mathrm{S}$ NPs, samples with different $\mathrm{Au} / \mathrm{Cu}$ ratios were selected, namely, $\mathrm{Au} @ \mathrm{Cu}-\mathrm{Sb}-\mathrm{S}(1-4) \mathrm{NPs}$ with $\mathrm{Au} / \mathrm{Cu}$ precursor ratio of 1:4 and $\mathrm{Au} @ \mathrm{Cu}-\mathrm{Sb}-\mathrm{S}(4-1) \mathrm{NPs}$ with $\mathrm{Au} / \mathrm{Cu}$ precursor ratio of 4:1. The UV-vis-NIR absorbance spectrum of Au@Cu-Sb-S(1-4) NPs and Au@Cu-Sb-S(4-1) NPs indicated that both samples showed concentration-dependent NIR absorption (Figure S3A and $\underline{B}$ ). The extinction coefficient of nanomaterials was obtained based on the Lambert-Beer law. ${ }^{37}$ As illustrated in Figure 1F, the extinction coefficient of Au@Cu-Sb-S (1-4) NPs and Au@Cu-Sb-S(4-1) NPs was $14 \mathrm{Lg}^{-1} \mathrm{~cm}^{-1}$ and $21 \mathrm{Lg}^{-1} \mathrm{~cm}^{-1}$, respectively, which was higher than that of Cu-Sb-S NPs $\left(10.5 \mathrm{Lg}^{-1} \mathrm{~cm}^{-1}\right)$ reported previously. ${ }^{22}$ This indicated that $\mathrm{Au} @ \mathrm{Cu}-\mathrm{Sb}-\mathrm{S}(4-1)$ NPs with more Au NCs on the surface exhibited better light absorption capacity than Au@Cu-Sb-S(1-4) NPs. ${ }^{38}$ The results shown in Figure 1G confirm this observation. The photothermal properties of the Au@Cu-Sb-S(1-4) NPs and Au@Cu-Sb-S(4-1) NPs were evaluated at different concentrations under $808 \mathrm{~nm}$ laser $\left(1 \mathrm{~W} \mathrm{~cm}^{-2}\right)$ irradiation (Figure S3C and D). The heating curves (Figure 1H) showed that the temperature of $\mathrm{Au} @ \mathrm{Cu}-\mathrm{Sb}-\mathrm{S}(1-4)$ and $\mathrm{Au} @ \mathrm{Cu}-\mathrm{Sb}-\mathrm{S}(4-1)$ solutions increased rapidly over time in a concentration-dependent manner. The temperature changes of $\mathrm{Cu}-\mathrm{Sb}-\mathrm{S}$ NPs, $\mathrm{Au} @ \mathrm{Cu}-\mathrm{Sb}-\mathrm{S}(1-4) \mathrm{NPs}$, and $\mathrm{Au} @ \mathrm{Cu}-\mathrm{Sb}-\mathrm{S}(4-1) \mathrm{NPs}$ were $21.9^{\circ} \mathrm{C}, 24.1{ }^{\circ} \mathrm{C}$, and $29.1^{\circ} \mathrm{C}$ during 600 s, respectively, which was higher than that of pure water $\left(4.7^{\circ} \mathrm{C}\right)$. The significant temperature increases ensure their performance in causing irreversible cell death due to hyperthermia. ${ }^{39}$ The photothermal stability of Au@Cu-Sb-S NPs was evaluated in four continuous heating-cooling cycles. As shown in Figure S4, the temperature change of NPs exhibited favorable stability and reproducibility during repeated cycles. These data strongly indicated that the Au@Cu-Sb-S NPs was a promising photothermal agent for further studies. By comparing the optical performance and photothermal performance of Au@Cu-Sb-S NPs with different Au/ $\mathrm{Cu}$ ratio, subsequent cell and animal experiments were conducted with $\mathrm{Au} @ \mathrm{Cu}-\mathrm{Sb}-\mathrm{S}(4-1) \mathrm{NPs}$ only.

\section{In vitro Cellular Studies}

The 4T1 cells were used to evaluate the cytotoxicity of Au@Cu-Sb-S NPs with the CCK-8 assay. As shown in Figure $2 \mathrm{~A}$, cell viabilities remained above $80 \%$ even at high concentrations (100 ppm Sb), demonstrating the negligible cytotoxicity of $\mathrm{Au} @ \mathrm{Cu}-\mathrm{Sb}-\mathrm{S}$ NPs.

$\mathrm{Au}$, a typical high $\mathrm{Z}$ element, can effectively absorb, disperse, and re-release radiation energy, and is the star material of radiotherapy sensitizers. ${ }^{40,41}$ In Figure 2A, the cell viability of the Only RT group and the Au@Cu-Sb-S group were higher than the Au@Cu-Sb-S + RT group, which proved that Au@Cu-Sb-S NPs had the effect of enhancing radiotherapy sensitivity. To further examine the radiation-enhancing effect of $\mathrm{Au} @ \mathrm{Cu}-\mathrm{Sb}-\mathrm{S}$ NPs, a colony formation assay was conducted. As shown in Figure $2 \mathrm{~B}$ and $\underline{\mathrm{S} 5}$, when exposed to the same irradiation dose, the survival rate of cells treated with nanoparticles was significantly lower than that of untreated cells. The cell viability decreased with increasing irradiation dose in both groups.

In addition to the sensitization effect of $\mathrm{Au} @ \mathrm{Cu}-\mathrm{Sb}-\mathrm{S}$ NPs, intracellular ROS production was explored using the reactive oxygen species (ROS) probe DCFH-DA. As shown in Figures 2C and $\underline{\mathrm{S} 6}$, ROS was higher in the Au@Cu-Sb-S NPs+RT group than in the RT alone group. Moreover, the $\mathrm{Au} @ \mathrm{Cu}-\mathrm{Sb}-\mathrm{S}$ NPs+NIR(ice) group operating on ice also had obvious ROS production. The most obvious green fluorescence was observed in the Au@Cu-Sb-S NPs+NIR+RT group, which could be attributed to the enhancement of ROS production by radiosensitizers in view of photo-radiotherapy. The results of the CCK-8 assay showed that the combination of $\mathrm{Au} @ \mathrm{Cu}-\mathrm{Sb}-\mathrm{S}+\mathrm{NIR}+\mathrm{RT}$ was significantly more cytotoxic to tumor cells than the other treatments at concentrations above $25 \mathrm{ppm} \mathrm{Sb}$ (Figure 2A). A similar cell survival trend was observed by live/dead cells staining (Figure 2D). The greatest cell killing effect was observed in the NPs+NIR+RT group, indicating that $\mathrm{Au} @ \mathrm{Cu}-\mathrm{Sb}-\mathrm{S}$ NPs had a phototherapy-enhanced synergistic effect with radiation therapy in $4 \mathrm{~T} 1$ cells. The flow cytometry results (Figure 2E) were consistent with those of live/dead cell staining experiments. Figure S7 showed that the apoptosis rates of cells in the $\mathrm{Au} @ \mathrm{Cu}-\mathrm{Sb}-\mathrm{S}+\mathrm{NIR}+\mathrm{RT}$ group were higher than the sum of the values in the $\mathrm{Au} @ \mathrm{Cu}-\mathrm{Sb}-\mathrm{S}+\mathrm{NIR}$ and $\mathrm{Au} @ \mathrm{Cu}-\mathrm{Sb}-\mathrm{S}+\mathrm{RT}$ groups at a concentration of $25 \mathrm{Sb}$ ppm. These results confirmed the potential of $\mathrm{Au} @ \mathrm{Cu}-\mathrm{Sb}-\mathrm{S}$ as an efficient radiosensitizer to inhibit the proliferation of cancer cell exposed to X-rays. 


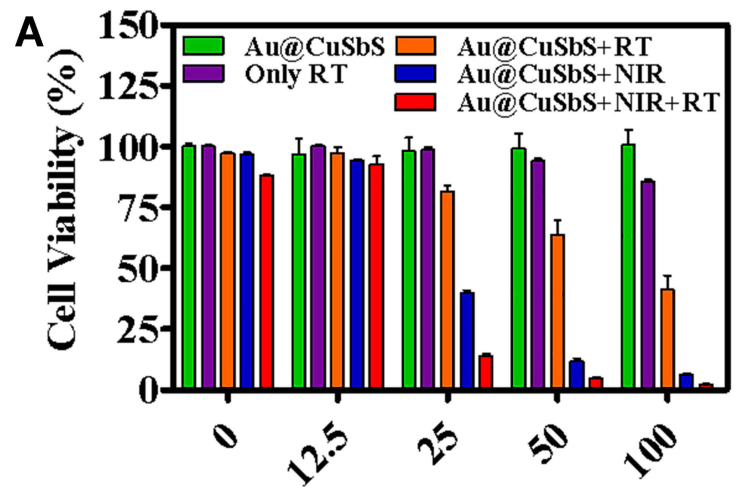

Sb Concentration (ppm)
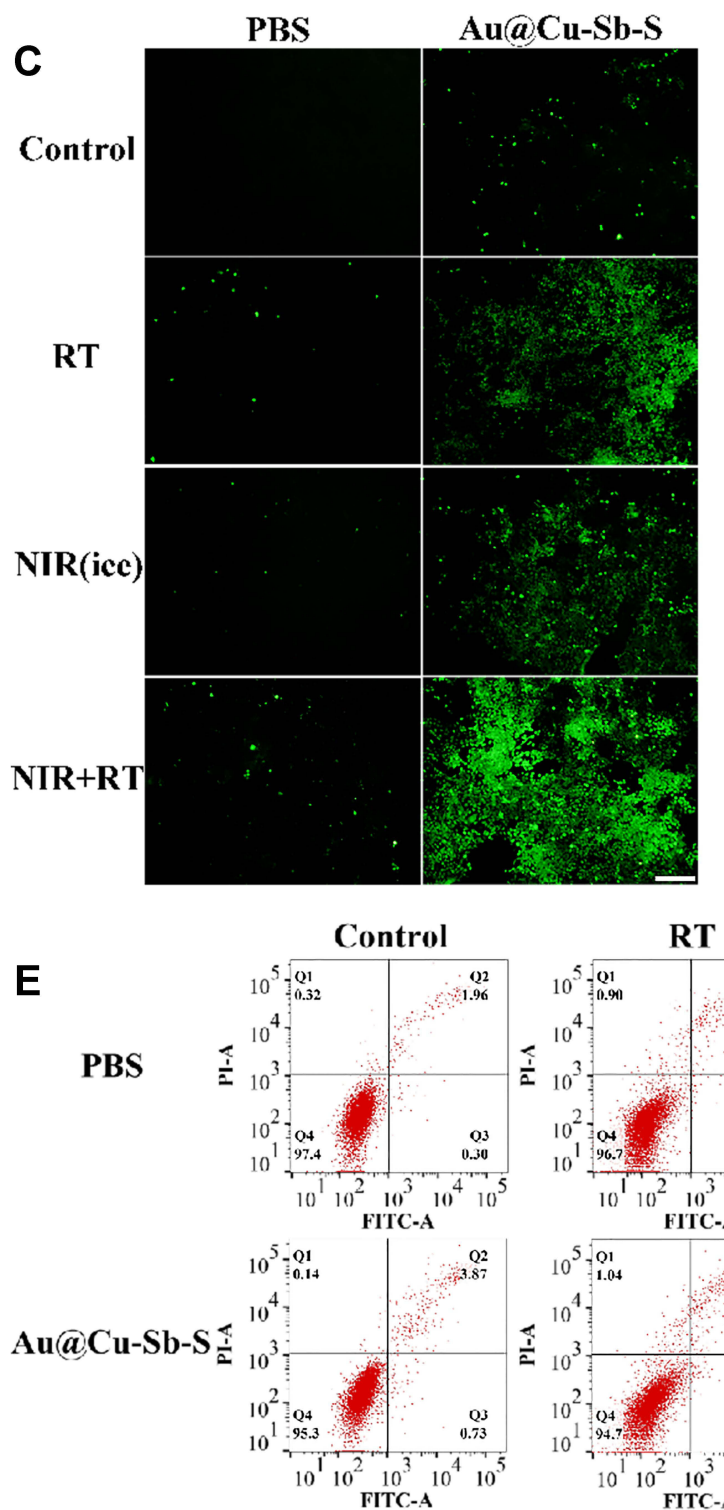
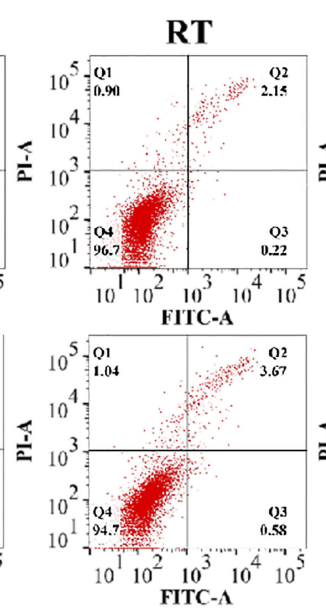
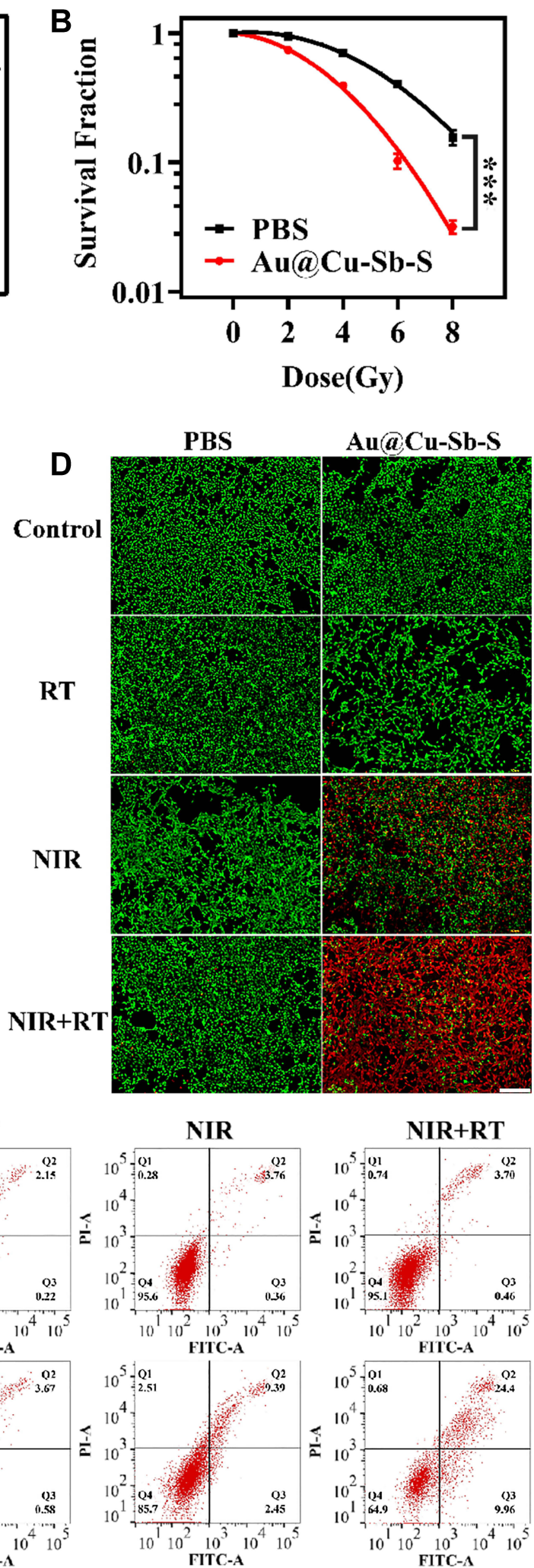

Figure 2 In vitro assessment of the therapeutic efficacy of Au@Cu-Sb-S nanoparticles (NPs). (A) Relative viability of 4TI cells exposed to different treatments at increased Sb concentrations. (Significant differences are represented as ***p $<0.001$.) (B) Clonogenic survival assay of 4TI cells incubated with PBS or Au@Cu-Sb-S NPs ( 25 Sb Ppm) and treated with X-rays at various doses. (C) Fluorescence images of 4TI cells stained with DCFH-DA. (D) Fluorescence images of 4TI cells stained with calcein-AM and PI after each treatment. (E) Cell apoptosis effects in 4TI cells subjected to with different treatments after incubation with PBS or Au@Cu-Sb-S NPs (25 Sb Ppm). 

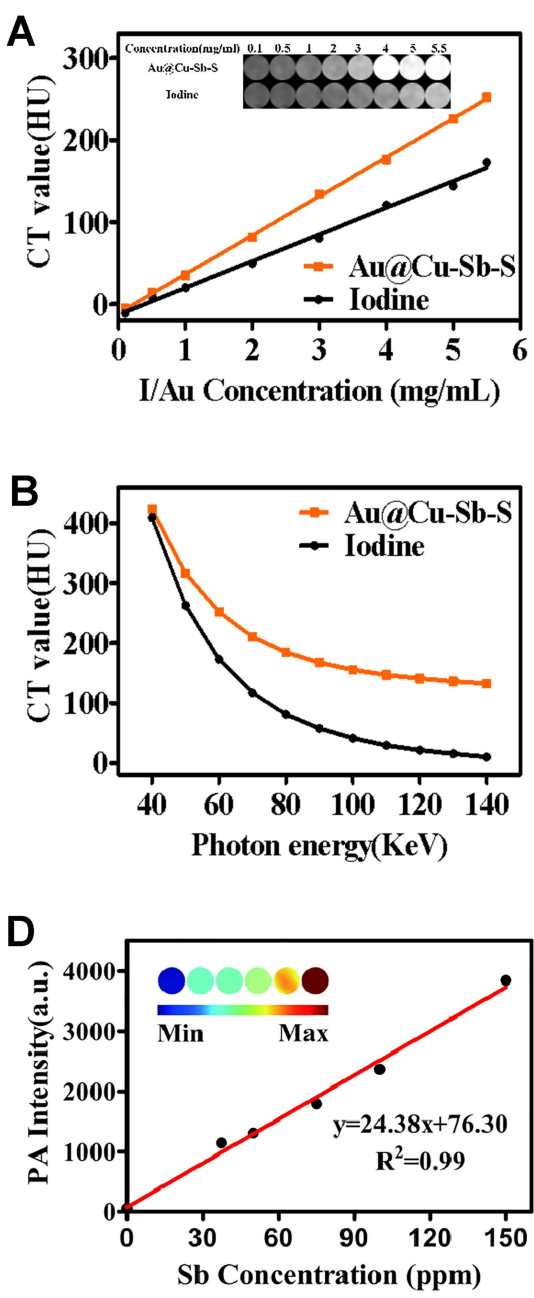

C $60 \mathrm{KeV}$ $100 \mathrm{KeV}$ $140 \mathrm{KeV}$
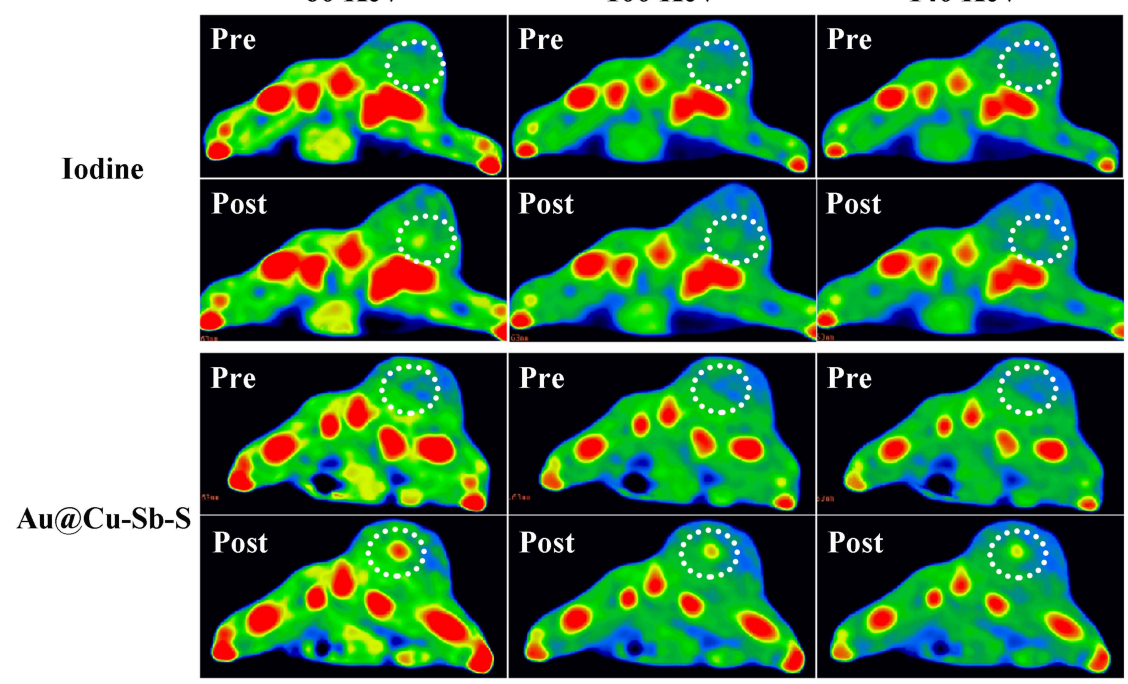

$\mathbf{E}$
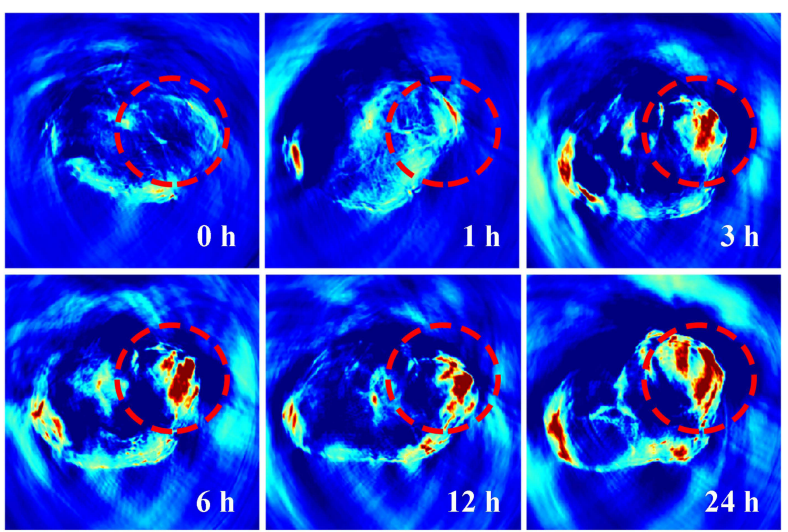

Max

Figure 3 Spectral computed tomography (CT) and photoacoustic (PA) imaging of Au@Cu-Sb-S nanoparticles (NPs) in vitro and in vivo. (A) CT brightness and intensity values of Au@Cu-Sb-S NPs and lodine at different concentrations under the $60 \mathrm{KeV}$ condition. (B) CT values of Au@Cu-Sb-S NPs and lodine with KeV changes under $5.5 \mathrm{mg} \mathrm{mL}^{-1} \mathrm{Au} / \mathrm{l}$ concentration. (C) In vivo spectral CT images of tumor-bearing mice before and after intra-tumoral injection of equivalent concentrations of Au @ Cu-Sb-S NPs and lodine (5.5 mg mL Au/l, $25 \mu \mathrm{L}$ ) at 60, 100, and I40 KeV. (D) Linear correlation between average PA signal intensity and Au@Cu-Sb-S NPs aqueous dispersion at different Sb concentrations. (E) In vivo PA imaging of 4TI tumor-bearing mice before and after injection of Au@Cu-Sb-S NPs.

\section{In vitro and in vivo Multimodal Imaging}

The high-Z elements, high-performance NIR absorption, and photothermal efficiency of Au@Cu-Sb-S NPs suggested that they were a potential CT/PA multimodal imaging contrast agent. The in vitro X-ray attenuation ability of $\mathrm{Au} @ \mathrm{Cu}-$ $\mathrm{Sb}-\mathrm{S}$ NPs was assessed by spectral CT imaging, and clinically used iodine was set as the control. Figure 3A shows that $\mathrm{Au} @ \mathrm{Cu}-\mathrm{Sb}-\mathrm{S}$ NPs exhibited a significantly enhanced brightness and higher HU values than iodine at different radiodense element concentrations. There was a linear relationship between the CT values and $\mathrm{Au} / \mathrm{I}$ concentrations at $60 \mathrm{KeV}$. The spectral CT value curves at different X-ray energies $(40-140 \mathrm{KeV})$ showed that the slope disparities between $\mathrm{Au} @ \mathrm{Cu}-\mathrm{Sb}-\mathrm{S}$ NPs and iodine became increasingly obvious at equivalent concentrations (Figure S8). The excellent CT imaging potential of $\mathrm{Au} @ \mathrm{Cu}-\mathrm{Sb}-\mathrm{S}$ NPs compared with clinical iodine at any concentration and $\mathrm{KeV}$ was confirmed in Figures 3B and $\underline{\mathrm{S}}$. These results demonstrated the superior attenuation coefficient of $\mathrm{Au} @ \mathrm{Cu}-\mathrm{Sb}-\mathrm{S}$ NPs on spectral CT imaging compared with clinical iodine.

Next, the capacity of $\mathrm{Au} @ \mathrm{Cu}-\mathrm{Sb}-\mathrm{S}$ NPs as a contrast agent for in vivo spectral CT was explored under different energies. As shown in Figure 3C, the contrast enhancement effect was remarkably improved after injection of NPs at single-energy imaging of $60 \mathrm{KeV}$. By contrast, the brightness in both groups became drastically weaker with increasing $\mathrm{KeV}$. A more obvious contrast enhancement of tumors was observed in the $\mathrm{Au} @ \mathrm{Cu}-\mathrm{Sb}$-S group under the same X-ray 
energy. When the injection concentration of nanomaterials was reduced to $2 \mathrm{mg} \mathrm{mL}^{-1}$, the contrast enhancement was hardly observed at 100 or $140 \mathrm{KeV}$, but could be clearly detected at $60 \mathrm{KeV}$ (Figure S10). This indicated that combining $\mathrm{Au} @ \mathrm{Cu}-\mathrm{Sb}-\mathrm{S}$ NPs with spectral CT may provide a sensitive diagnostic tool for tumor imaging, which will greatly benefit spatially accurate imaging-guided irradiation.

The PA imaging of Au@Cu-Sb-S NPs was also investigated. The PA spectrum of NPs (Figure S11) confirmed that the wavelength of $780 \mathrm{~nm}$ was the most sensitive to the excitation of the material's photoacoustic signal. As shown in Figure 3D, the PA signal values of Au@Cu-Sb-S NPs were concentration-dependent. In the in vivo experiment (Figure 3E), intravenous injection of $\mathrm{Au} @ \mathrm{Cu}-\mathrm{Sb}-\mathrm{S}$ NPs had a remarkable PA signal brightening effect in the tumor region at $24 \mathrm{~h}$. These results indicated that $\mathrm{Au} @ \mathrm{Cu}-\mathrm{Sb}-\mathrm{S}$ NPs may serve as a promising contrast agent for dual-modal spectral CT and PA imaging.

\section{In vivo Synergetic Radio-Phototherapy in a Tumor-Bearing Mouse Model}

For the in vivo therapy studies, 4T1 tumor-bearing mice were randomly divided into five groups as follows: saline, $\mathrm{Au} @ \mathrm{Cu}-\mathrm{Sb}-\mathrm{S}, \mathrm{Au} @ \mathrm{Cu}-\mathrm{Sb}-\mathrm{S}+\mathrm{NIR}, \mathrm{Au} @ \mathrm{Cu}-\mathrm{Sb}-\mathrm{S}+\mathrm{RT}$, and Au@Cu-Sb-S+NIR+RT. The infrared images and heating curves of the tumor site were obtained at $24 \mathrm{~h}$ after injection under NIR irradiation using an IR thermograph (Figure 4A and B). After laser irradiation for 5 minutes, the temperature of the tumor site in mice treated with $\mathrm{Au} @ \mathrm{Cu}-\mathrm{Sb}-\mathrm{S}$ NPs reached $47.5^{\circ} \mathrm{C}$, whereas the temperature of mice injected with saline only remained at $39.1^{\circ} \mathrm{C}$. This demonstrated that $\mathrm{Au} @ \mathrm{Cu}-\mathrm{Sb}-\mathrm{S}$ NPs could serve as an excellent phototherapy agent to induce hyperthermia under laser irradiation.

The body weight and tumor volume of mice in each group were recorded every other day during the treatment period (Figure 4C and D). No significant weight loss was observed in the treated and control groups. The volume of tumors treated with $\mathrm{Au} @ \mathrm{Cu}-\mathrm{Sb}-\mathrm{S}+\mathrm{NIR}+\mathrm{RT}$ decreased after treatment and tumors almost completely disappeared (97.6\%) on day 21 , whereas the tumors in all other groups continued to grow although at different rates. The representative photographs, HE, and TUNEL staining confirmed the enhanced treatment efficacy in the $\mathrm{Au} @ \mathrm{Cu}-\mathrm{Sb}-\mathrm{S}+\mathrm{NIR}+\mathrm{RT}$ group (Figure 4E). These results confirmed the synergistic photo-radiotherapeutic effect induced by $\mathrm{Au} @ \mathrm{Cu}-\mathrm{Sb}-\mathrm{S}$ NPs in vivo.

\section{In vivo Toxicity and Bio-Distribution Studies}

The in vivo toxicity of Au@Cu-Sb-S NPs was also evaluated. Major organs (heart, liver, spleen, lung, and kidney) were subjected to HE staining after injection of $\mathrm{Au} @ \mathrm{Cu}-\mathrm{Sb}-\mathrm{S}$ NPs. As shown in Figure S12, there was no noticeable damage to normal tissues. The results of blood analysis suggested good biological safety of $\mathrm{Au} @ \mathrm{Cu}-\mathrm{Sb}-\mathrm{S}$ NPs (Figure S13), which was consistent with the unchanged body weight of mice. Taken together, these results indicated that $\mathrm{Au} @ \mathrm{Cu}-\mathrm{Sb}-\mathrm{S}$ NPs was a safe nanoplatform for tumor theranostics. Figure S14 demonstrated that NPs began to accumulate in the tumor $3 \mathrm{~h}$ after tail vein injection, and the maximum enrichment was at $24 \mathrm{~h}$.

\section{Conclusion}

In conclusion, multifunctional $\mathrm{Au} @ \mathrm{Cu}-\mathrm{Sb}-\mathrm{S}$ NPs were successfully developed as a theranostic nanoplatform for spectral CT/PA bioimaging-guided synergistic photo-radiotherapy in breast cancer. Cells incubated with the asprepared $\mathrm{Au} @ \mathrm{Cu}-\mathrm{Sb}-\mathrm{S}$ NPs showed viabilities above 80\% even at high concentrations (100 ppm Sb), demonstrating the negligible cytotoxicity of $\mathrm{Au} @ \mathrm{Cu}-\mathrm{Sb}-\mathrm{S}$ NPs in vitro. H\&E staining and blood analysis demonstrated there was no noticeable damage to normal tissues, indicating relatively satisfactory biocompatibility and physiological stability in vivo. The Au@Cu-Sb-S NPs showed excellent NIR absorbance with remarkable photothermal efficiency. Because of the aggregation of the high-Z element $\mathrm{Au}, \mathrm{Au} @ \mathrm{Cu}-\mathrm{Sb}-\mathrm{S}$ NPs exhibited strong contrast enhancement on spectral $\mathrm{CT}$ and highly efficient radio-sensitization for RT. The cell apoptosis ratio of $\mathrm{Au} @ \mathrm{Cu}-\mathrm{Sb}-\mathrm{S}+\mathrm{NIR}+\mathrm{RT}$ group was $34.6 \%$, which was noticeably higher than other treatment groups (the cell apoptosis ratio treated with Au@Cu-Sb-S +NIR and Au@Cu-Sb-S+RT were 11.4\% and 4.9\%, respectively). The tumor volume treated with Au@Cu-Sb-S $+\mathrm{NIR}+\mathrm{RT}$ decreased after treatment, and the tumor almost completely disappeared on the 21 st day (97.6\%), whereas 
A

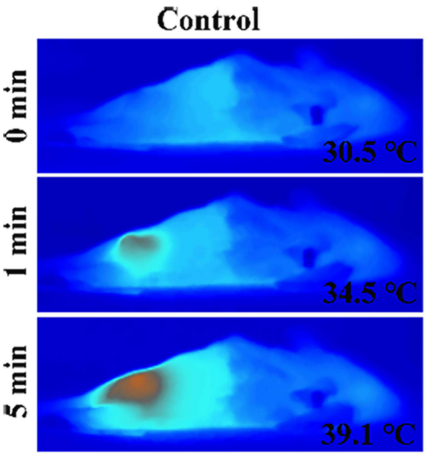

C

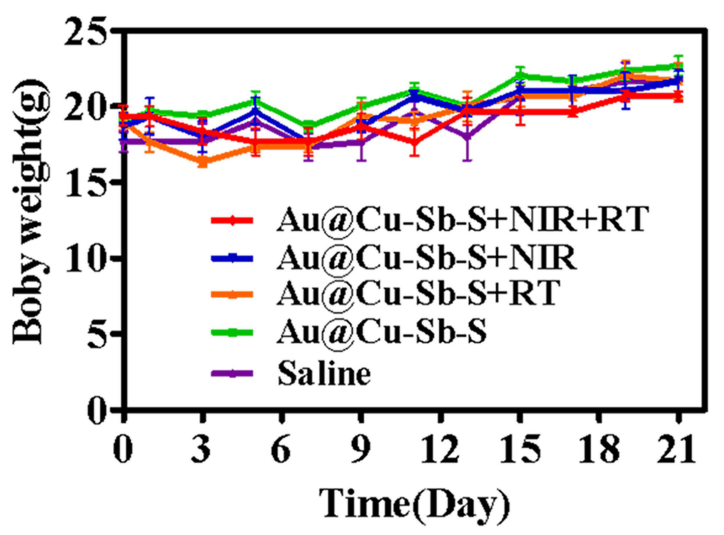

$\mathrm{Au} @ \mathbf{C u}-\mathbf{S b}-\mathbf{S}$
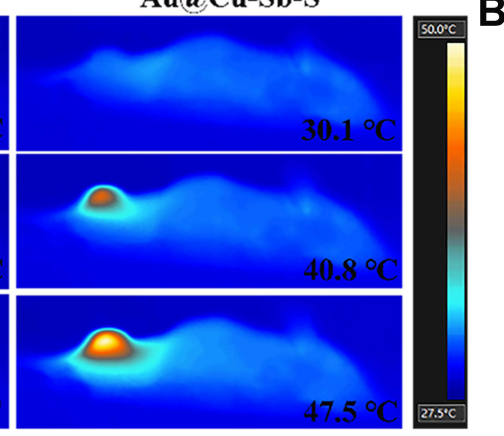

B

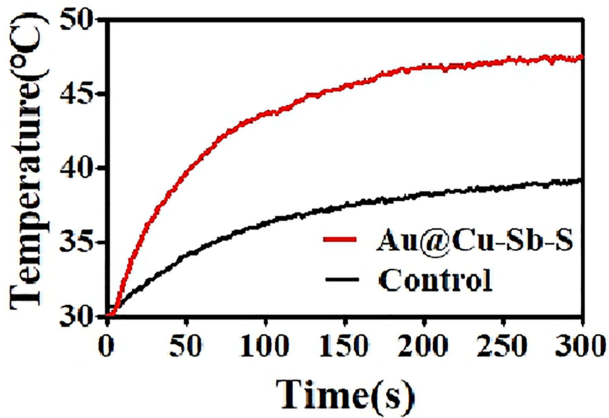

$E$

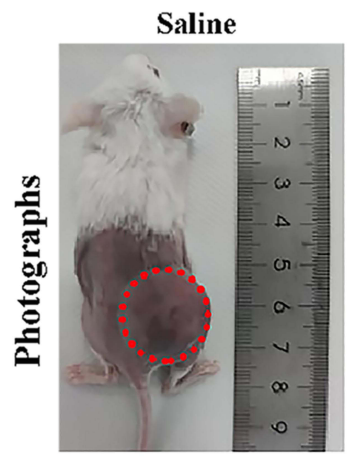

Au@Cu-Sb-S

$\mathrm{Au} @ \mathrm{Cu}-\mathrm{Sb}-\mathrm{S}+\mathrm{RT}$
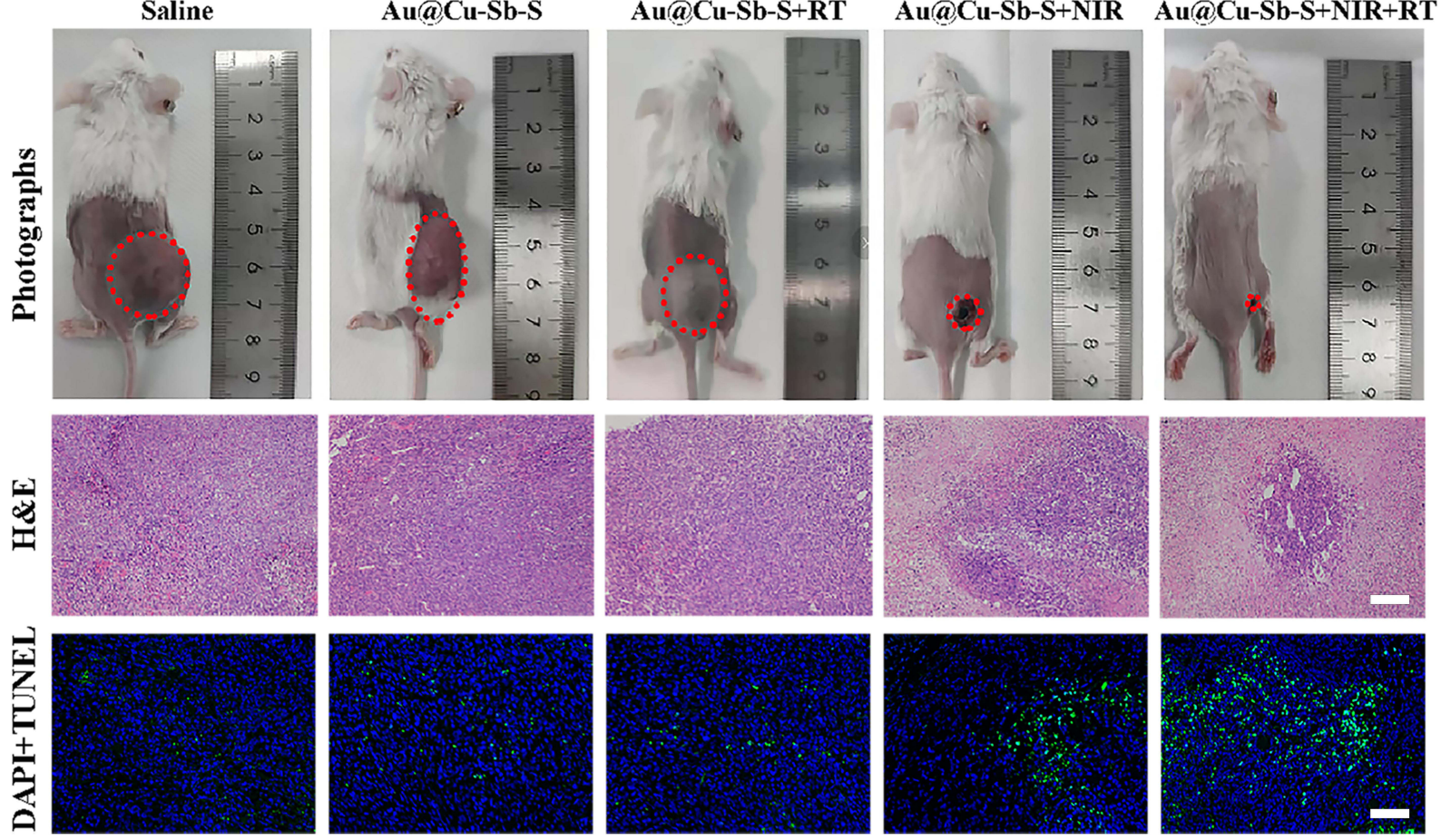

Figure 4 Therapeutic effect of Au@Cu-Sb-S nanoparticles (NPs) in vivo. (A) Infrared thermal images and (B) temperature changes of BALB/c mice bearing 4TI tumors after injection of saline (left) or Au@Cu-Sb-S NPs (right), followed by irradiation with a continuous NIR laser. (C) Time-dependent body weight and (D) tumor growth curves of $4 \mathrm{TI}$ tumor-bearing nude mice from each group. The statistical differences were assessed using one-way ANOVA (*** $p<0.00 \mathrm{I})$. (E) Digital photographs of mice on day $2 \mathrm{I}$ after various treatments, H\&E staining and TUNEL staining of tumors are shown. 
the tumors in all other groups continued to grow, albeit at different rates. The treatment effect of $\mathrm{Au} @ \mathrm{Cu}-\mathrm{Sb}-\mathrm{S}+\mathrm{NIR}$ +RT group on tumor was significantly better than other groups. The present results suggested that $\mathrm{Au} @ \mathrm{Cu}-\mathrm{Sb}-\mathrm{S} \mathrm{NPs}$ was a promising multi-modal imaging nanoplatform to guide synergistic photo-radiotherapy for future translational cancer therapy.

\section{Acknowledgments}

This work was supported by the National Natural Science Foundation of China (grant numbers: 81871334, 81801764, 82072056, and 51937010); the Guangdong Basic and Applied Basic Research Foundation (grant numbers: 2017A050506011, 2018030310343, 2020B1515020008, 2021A1515012542 and 2021A1515011882); the Medical Scientific Research Foundation of Guangdong Province (grant number: A2018014), and the Pearl River Talented Young Scholar Program (grant number: 2017GC010282).

The authors would like to thank Guangzhou Institute of Energy Conversion Chinese Academy of Sciences for TEM and HRTEM characterizations and Sun Yat-Sen University Instrumental Analysis \& Research Center for XRD characterization.

\section{Disclosure}

The authors declare no conflicts of interest in this work.

\section{References}

1. Brunt A, Haviland J, Sydenham M, et al. Ten-year results of FAST: a randomized controlled trial of 5-fraction whole-breast radiotherapy for early breast cancer. J Clin Oncol. 2020;38(28):3261-3272. doi:10.1200/jco.19.02750

2. Buckley AM, Lynam-Lennon N, O'Neill H, O'Sullivan J. Targeting hallmarks of cancer to enhance radiosensitivity in gastrointestinal cancers. Nat Rev Gastroenterol Hepatol. 2020;17(5):298-313. doi:10.1038/s41575-019-0247-2

3. Kirakci K, Pozmogova T, Protasevich A, et al. A water-soluble octahedral molybdenum cluster complex as a potential agent for X-ray induced photodynamic therapy. Biomater Sci. 2021;9(8):2893-2902. doi:10.1039/d0bm02005b

4. Li SM, Tan LF, Meng XW. Nanoscale metal-organic frameworks: synthesis, biocompatibility, imaging applications, and thermal and dynamic therapy of tumors. Adv Funct Mater. 2020;30(13). doi:10.1002/adfm.201908924

5. Guo Z, Zhu S, Yong Y, et al. Synthesis of BSA-coated BiOI@Bi2 S3 semiconductor heterojunction nanoparticles and their applications for radio/ photodynamic/photothermal synergistic therapy of tumor. Adv Mater. 2017;29(44):1704136. doi:10.1002/adma.201704136

6. Liu TI, Lu TY, Yang YC, et al. New combination treatment from ROS-Induced sensitized radiotherapy with nanophototherapeutics to fully eradicate orthotopic breast cancer and inhibit metastasis. Biomaterials. 2020;257:120229. doi:10.1016/j.biomaterials.2020.120229

7. Gong L, Zhang Y, Liu C, Zhang M, Han S. Application of radiosensitizers in cancer radiotherapy. Int J Nanomedicine. 2021;16:1083-1102. doi:10.2147/ijn.S290438

8. Li XS, Lovell JF, Yoon J, Chen XY. Clinical development and potential of photothermal and photodynamic therapies for cancer. Nat Rev Clin Oncol. 2020;17(11):657-674. doi:10.1038/s41571-020-0410-2

9. Xie ZJ, Fan TJ, An JS, et al. Emerging combination strategies with phototherapy in cancer nanomedicine. Chem Soc Rev. 2020;49(22):8065-8087. doi: $10.1039 / \mathrm{d} 0 \operatorname{cs} 00215 \mathrm{a}$

10. Wang X, Zhang CY, Du JF, et al. Enhanced generation of non-oxygen dependent free radicals by Schottky-type heterostructures of Au-BiS nanoparticles via X-ray-induced catalytic reaction for radiosensitization. ACS Nano. 2019;13(5):5947-5958. doi:10.1021/acsnano.9b01818

11. Oliveira J, Guidelli E. Multitherapeutic nanoplatform based on scintillating anthracene, silver@anthracene, and gold@anthracene nanoparticles for combined radiation and photodynamic cancer therapies. Mater Sci Eng C Mater Biol Appl. 2021;126:112122. doi:10.1016/j.msec.2021.112122

12. Chang MY, Hou ZY, Wang M, et al. Cu2 MoS4 /Au heterostructures with enhanced catalase-like activity and photoconversion efficiency for primary/metastatic tumors eradication by phototherapy-induced immunotherapy. Small. 2020;16(14):e1907146. doi:10.1002/smll.201907146

13. Yang S, Han GH, Chen Q, et al. Au-Pt nanoparticle formulation as a radiosensitizer for radiotherapy with dual effects. Int $J$ Nanomedicine. 2021;16:239-248. doi:10.2147/IJN.S287523

14. Zhang P, Yu B, Jin X, et al. Therapeutic efficacy of carbon ion irradiation enhanced by 11-MUA-capped gold nanoparticles: an in vitro and in vivo study. Int J Nanomedicine. 2021;16:4661-4674. doi:10.2147/IJN.S313678

15. Chen Y, Yang J, Fu S, Wu J. Gold nanoparticles as radiosensitizers in cancer radiotherapy. Int J Nanomedicine. 2020;15:9407-9430. doi:10.2147/ ijn.S272902

16. Zhang J, Liu YT, Wang X, et al. Nanozyme-incorporated biodegradable bismuth mesoporous radiosensitizer for tumor microenvironmentmodulated hypoxic tumor thermoradiotherapy. ACS Appl Mater Interfaces. 2020;12(52):57768-57781. doi:10.1021/acsami.0c18853

17. Liu HX, Lin WQ, He LZ, Chen TF. Radiosensitive core/satellite ternary heteronanostructure for multimodal imaging-guided synergistic cancer radiotherapy. Biomaterials. 2020;226:119545. doi:10.1016/j.biomaterials.2019.119545

18. Zhou J, Geng SZ, Ye WR, et al. ROS-boosted photodynamic therapy against metastatic melanoma by inhibiting the activity of antioxidase and oxygen-producing nano-dopants. Pharmacol Res. 2020;158:104885. doi:10.1016/j.phrs.2020.104885

19. Yaqoob S, Adnan R, Rameez Khan R, Rashid M. Gold, silver, and palladium nanoparticles: a chemical tool for biomedical applications. Front Chem. 2020;8:376. doi:10.3389/fchem.2020.00376 
20. Huang Q, Zhang SH, Zhang H, et al. Boosting the radiosensitizing and photothermal performance of Cu2- xSe nanocrystals for synergetic radiophotothermal therapy of orthotopic breast cancer. ACS Nano. 2019;13(2):1342-1353. doi:10.1021/acsnano.8b06795

21. Nosrati H, Charmi J, Abhari F, et al. Improved synergic therapeutic effects of chemoradiation therapy with the aid of a co-drug-loaded nanoradiosensitizer under conventional-dose X-ray irradiation. Biomater Sci. 2020;8(15):4275-4286. doi:10.1039/d0bm00353k

22. Hou MR, Yan CG, Chen ZL, et al. Multifunctional NIR-responsive poly(vinylpyrrolidone)-Cu-Sb-S nanotheranostic agent for photoacoustic imaging and photothermal/photodynamic therapy. Acta Biomater. 2018;74:334-343. doi:10.1016/j.actbio.2018.05.011

23. Ding XG, Liow $\mathrm{CH}$, Zhang MX, et al. Surface plasmon resonance enhanced light absorption and photothermal therapy in the second near-infrared window. J Am Chem Soc. 2014;136(44):15684-15693. doi:10.1021/ja508641z

24. Wang XL, Liu X, Zhu DW, Swihart MT. Controllable conversion of plasmonic Cu2-xS nanoparticles to Au2S by cation exchange and electron beam induced transformation of $\mathrm{Cu} 2-\mathrm{xS}-\mathrm{Au} 2 \mathrm{~S}$ core/shell nanostructures. Nanoscale. 2014;6(15):8852-8857. doi:10.1039/c4nr02114b

25. Tao C, An L, Lin JM, Tian QW, Yang SP. Surface plasmon resonance-enhanced photoacoustic imaging and photothermal therapy of endogenous H2 S-triggered Au@Cu2 O. Small. 2019;15(44):e1903473. doi:10.1002/smll.201903473

26. Lu SY, Li X, Zhang JL, Peng C, Shen MW, Shi XY. Dendrimer-stabilized gold nanoflowers embedded with ultrasmall iron oxide nanoparticles for multimode imaging-guided combination therapy of tumors. Adv Sci. 2018;5(12):1801612. doi:10.1002/advs.201801612

27. Li SN, Zhang LY, Chen XJ, et al. Selective growth synthesis of ternary janus nanoparticles for imaging-guided synergistic chemo- and photothermal therapy in the second NIR window. ACS Appl Mater Interfaces. 2018;10(28):24137-24148. doi:10.1021/acsami.8b06527

28. He F, Ji HJ, Feng LL, et al. Construction of thiol-capped ultrasmall Au-Bi bimetallic nanoparticles for X-ray CT imaging and enhanced antitumor therapy efficiency. Biomaterials. 2021;264:120453. doi:10.1016/j.biomaterials.2020.120453

29. Wang M, Chang MY, Chen Q, et al. Au2Pt-PEG-Ce6 nanoformulation with dual nanozyme activities for synergistic chemodynamic therapy/ phototherapy. Biomaterials. 2020;252:120093. doi:10.1016/j.biomaterials.2020.120093

30. Taheri-Ledari R, Zhang W, Radmanesh M, et al. Multi-stimuli nanocomposite therapeutic: docetaxel targeted delivery and synergies in treatment of human breast cancer tumor. Small. 2020;16(41):e2002733. doi:10.1002/smll.202002733

31. Metin Y, Metin NO, Ozdemir O, Tasci F, Kul S. The role of low keV virtual monochromatic imaging in increasing the conspicuity of primary breast cancer in dual-energy spectral thoracic CT examination for staging purposes. Acta Radiol. 2020;61(2):168-174. doi:10.1177/0284185119858040

32. Wu J, Yang X, Gao JM, Zhao S, Wang L, Luo TY. Application of MRI and CT energy spectrum imaging in hand and foot tendon lesions. $J$ Med Syst. 2019;43(5):116. doi:10.1007/s10916-019-1208-6

33. Yuan R, Shuman W, Earls J, et al. Reduced iodine load at CT pulmonary angiography with dual-energy monochromatic imaging: comparison with standard CT pulmonary angiography-a prospective randomized trial. Radiology. 2012;262(1):290-297. doi:10.1148/radiol.11110648

34. Jia XQ, Li XJ, Li JY, et al. Improving diagnostic accuracy for arteries of lower extremities with dual-energy spectral CT imaging. Eur J Radiol. 2020;128:109061. doi:10.1016/j.ejrad.2020.109061

35. Wang GK, Zhao DL, Ling ZS, Wang HB, Yu SS, Zhang JL. Evaluation of the best single-energy scanning in energy spectrum CT in lower extremity arteriography. Exp Ther Med. 2019;18(2):1433-1439. doi:10.3892/etm.2019.7666

36. Zhao JH, Chai YJ, Zhou JL, Zhang ZL, Wang ZP. Energy spectrum computed tomography improves the differentiation between benign and malignant solitary pulmonary nodules. Clin Invest Med. 2019;42(3):E40-E46. doi:10.25011/cim.v42i3.33091

37. Jiang XX, Zhang SH, Ren F, et al. Ultrasmall magnetic CuFeSe2 ternary nanocrystals for multimodal imaging guided photothermal therapy of cancer. ACS Nano. 2017;11(6):5633-5645. doi:10.1021/acsnano.7b01032

38. Zhu H, Wang Y, Chen C, et al. Monodisperse dual plasmonic Au@CuE (E= S, Se) core@shell supraparticles: aqueous fabrication, multimodal imaging, and tumor therapy at in vivo level. ACS Nano. 2017;11(8):8273-8281. doi:10.1021/acsnano.7b03369

39. Jaque D, Martinez Maestro L, Del Rosal B, et al. Nanoparticles for photothermal therapies. Nanoscale. 2014;6(16):9494-9530. doi:10.1039/ c4nr00708e

40. Sun WJ, Luo L, Feng YS, et al. Aggregation-induced emission gold clustoluminogens for enhanced low-dose X-ray-induced photodynamic therapy. Angew Chem Int Ed Engl. 2020;59(25):9914-9921. doi:10.1002/anie.201908712

41. Xia DL, Hang DM, Li YY, et al. Au-hemoglobin loaded platelet alleviating tumor hypoxia and enhancing the radiotherapy effect with low-dose X-ray. ACS Nano. 2020;14(11):15654-15668. doi:10.1021/acsnano.0c06541

International Journal of Nanomedicine

Dovepress

\section{Publish your work in this journal}

The International Journal of Nanomedicine is an international, peer-reviewed journal focusing on the application of nanotechnology in diagnostics, therapeutics, and drug delivery systems throughout the biomedical field. This journal is indexed on PubMed Central, MedLine, CAS, SciSearch ${ }^{\circledR}$, Current Contents ${ }^{\circledR} /$ Clinical Medicine, Journal Citation Reports/Science Edition, EMBase, Scopus and the Elsevier Bibliographic databases. The manuscript management system is completely online and includes a very quick and fair peer-review system, which is all easy to use. Visit http:// www.dovepress.com/testimonials.php to read real quotes from published authors.

Submit your manuscript here: https://www.dovepress.com/international-journal-of-nanomedicine-journal 